\title{
Relationship between HIV Positive Status Announcement and Smoking among Infected-Individuals in Bamako, Mali
}

Bocar Baya ${ }^{1,2^{\star}}$, Cheick Abdel Kader Maiga ${ }^{3}$, Yeya dit Sadio Sarro, Mamadou Cisse ${ }^{3}$, Eleazar Dao ${ }^{2}$, Sidiki Sangare $^{2}$, Sounkalo Dao $^{1,4}$ and Souleymane Diallo ${ }^{1,2}$

${ }^{1}$ HIV/TB Research and Training Center (SEREFO), Faculty of Medicine, Odontostomatology and Faculty of Pharmacy (FMOS \& FPHA), University of Sciences, Techniques and Technologies of Bamako (USTTB), Bamako, Mali

${ }^{2}$ Pneumo-phtisiologie department, Point G University Hospital, Bamako, Mali

${ }^{3}$ Centre d'Ecoute de Soins et d'Accompagnement (CESAC), Association de Recherche, de Communication et d'Accompagnement à Domicile des personnes vivant avec le VIH (ARCAD/SIDA) Bamako, Mali

${ }^{4}$ Infectious Diseases department, Point G University Hospital, Bamako, Mali

\begin{abstract}
Background: The announcement of HIV-positive status is a critical moment of psycho-social destabilization that can induce changes in the behavior of an individual such a beginning or increased tobacco consumption

Objective: The objective was to study the relationship between the HIV positive status announcement and smoking behavior among people living with human immunodeficiency virus (HIV) in Bamako after the discovering their status.

Methods: We did a descriptive cross-sectional study over six months from January to June 2012. Data were collected by interviewing HIV infected patients in three health care centers, departments of pulmonary diseases, department of infectious and tropical diseases and the largest HIV clinic in Mali (CESAC of Bamako). All participants have signed an informed consent before the interview. Data were analyzed using Epi-Info version 7.1.5.2 software.

Results: A total of $301 \mathrm{HIV}$-infected people were included, $24 \%$ patients were current smokers $6.3 \%$ former smokers and $69.7 \%$ non-smokers. Smokers were male in majority with $93.2 \%$. After their HIV infection status announcement, $64.9 \%$ have increased their tobacco consumption while $10.8 \%$ have decreased their consumption. Majority of patients have a good knowledge of the health risks of smoking. Of those who continue to smoke, $83.8 \%$ reported that they tried and fail to stop smoking at least one time. The main reason of their cessation was the effect on their health. And the main reason for the failure was the constant thinking of the disease.
\end{abstract}

Conclusion: The announcement of the HIV positivity status must be accompanied by psychosocial support helping to overcome the emotion and stress and a smoking cessation program must be added to HIV screening program.

Keywords: HIV; Announcement; Smoking; Mali

\section{Introduction}

Cigarette smoking remains at least twice as prevalent as in the general population worldwide [1]. In 2015, in United States the prevalence was estimated to be $19.0 \%$ in HIV-infected population [2]. In Brazil, the prevalence was $29.9 \%$ among HIV-infected in care in Rio [3]. A study in Europe and North America has found a prevalence of $60 \%$ and twice death rate in smoking group compare to non-smoking group [4]. In Danish cohort, Davidsen et al. reported that smoking was responsible for $24 \%$ of all deaths and $17 \%$ of all hospital admissions [5]. In Malian, in 2013, the prevalence of HIV in the general population was $1.1 \%$. But in Bamako the capital it was about 3\% [6]. In 2010, WHO estimated that $17 \%$ of Malian population smoked (32\% of men and $3 \%$ of women smoked) [7]. Many studies have been published in the world on HIV infected population smoking high rate, more consequences and different smoking cessation methods. But we did not found data on studies which have raised the question on what factor could have influenced HIV-infected individuals to smoke more or impacted their quitting decision and what have been the different factors that could increase their smoking rate. However, Anselm et al. in 2012, have described that chronic stress, or ongoing difficult conditions of daily life as well as recent life events were significantly, positively associated with higher self-reported impulsivity, and impulsivity was associated with current smoking status [8]. In Mali no study was conducted on HIV and smoking relationship. We therefore proposed to study the possible interaction between the HIV positive result announcement and smoking beginning or increasing. We hypothesized that HIV positivity announcement is a critical time for a patient who can initiate or re initiate tobacco smoking or increase its consumption. The purpose of this study was to investigate the relationship of HIV positive status announcement and its impact on patients smoking behavior in Bamako, Mali. The primary objective was to describe the relationship between the announcement of the HIV positive status and smoking. The Secondary objectives were to:

-Determine the frequency of tobacco smoking among HIV-infected patients seen in the three largest HIV clinics in Bamako, Mali.

-Describe HIV-infected patients smoking behavior after being informed of their VIH-infection.

*Corresponding author: Bocar Baya, MD, Practitioner at Pneumo-phtisiology department, University Hospital of Point-G, Associate Clinical Investigator at SEREFO (HIV/TB Research and Training Center) at Faculty of Medicine, Odonstomatology and Faculty of Pharmacy (FMOS\&FPHA)/University of Sciences Techniques and Technologies of Bamako (USTTB), Mali, Tel: +223 76377023 E-mail: bbaya@icermali.org

Received August 12, 2016; Accepted September 01, 2016; Published September 08, 2016

Citation: Baya B, Maiga CAK, Sarro YdS, Cisse M, Dao E, et al. (2016) Relationship between HIV Positive Status Announcement and Smoking among Infected-Individuals in Bamako, Mali. J AIDS Clin Res 7: 617. doi:10.4172/21556113.1000617

Copyright: (c) 2016 Baya B, et al. This is an open-access article distributed under the terms of the Creative Commons Attribution License, which permits unrestricted use, distribution, and reproduction in any medium, provided the original author and source are credited. 
-Determine the knowledge of HIV-infected patients on smoking dangers.

-Describe common clinical events in HIV-infected patients who smoked compare to never smoke.

\section{Methods}

We conducted a descriptive cross sectional study from January to September 2012 in three largest HIV clinics in Bamako, Mali. Two in Point G University Hospital (the department of infectious and tropical diseases and the department of pneumophtisiology) and CESAC (Center d'Ecoute, de Soins et d'Accompaniment), the largest center for HIV care. HIV-positive volunteers aged 18 years old or more were included in this study after signing the informed consent form willing to be informed about their HIV testing result and were followed in one of the three health centers for routine care. The inclusion criteria were all HIV-positive patients whose HIV status were announced to them and were followed for routine care (for antiretroviral therapy monitoring or treatment not yet started) in CESAC clinic or infectious disease department at Point hospital or whose were seen at Point G pulmonary disease department for respiratory complications. All patients should have signed an informed consent form to participate to the survey. We excluded all patients whose HIV positive status announcement were not done by a health care professional or whose were not convinced to their status positive status or HIV positive patients who refused to participate to the study. Data were collected on anonymous individual questionnaire sheet. We collected demographic data, HIV testing circumstances, smoking information. Epi-Info software version 7.1.5.2. Percentages were compared using Fisher test. $\mathrm{P}$ values $<0.05$ were considered as significant. Written informed consent has been obtained from all the volunteers prior to answer to the questionnaire. Inform consent was explained in local language for non-French speaking volunteers. The questionnaires were anonymous, patient record number served as link to his source document. Data will be exclusively used for scientific reasons. The study was fully funded by the rectorate of the University of Sciences, Techniques and Technologies of Bamako (USTT-B), Mali.

\section{Results}

Three hundred and one HIV-infected patients, aged from 18 to 66 years in three largest HIV clinics where were interviewed (Figure 1). One hundred and fifty-two (50.5\%) were seen in CESAC, 125 (41.5\%) in infectious and tropical disease department and 24 (8\%) in Pneumophtisiology department. Females were predominant, 173 (57.5\%) and males were 128 (42.5\%). Age ranges $18-35$ and 36-50 years were most represented respectively $43.5 \%$ and $42.2 \%$. The mean age was 38.5 years. Married participants were $64.1 \%$, followed by single $(18.3 \%)$ and widowed (11.0\%). The study population has $43.2 \%$ as illiterate; primary and secondary school level were respectively $33.2 \%$ and $18.0 \%$. The frequency of HIV-1 infection was $97.67 \%$ in our study population and $87 \%$ were under antiretroviral therapy. The main reason for the study population to undergo HIV testing was an investigation for an unknown disease symptoms (78.7\%) and $11.6 \%$ were for testing screening. The main occupations of our study population were Housewife, trader and farmer respectively $27.6 \%, 25.2 \%, 20.6 \%$. Most of the participants, (82.7\%) known their HIV-infection status at least 6 months before the beginning of One hundred and seventy-eight (59.0\%) did not travel outside the country, 38.0\% have traveled to another country in Africa and 3.0\% to another continent (Table 1).

A total of 93 (30.9\%) out of 301 patients have been exposed to

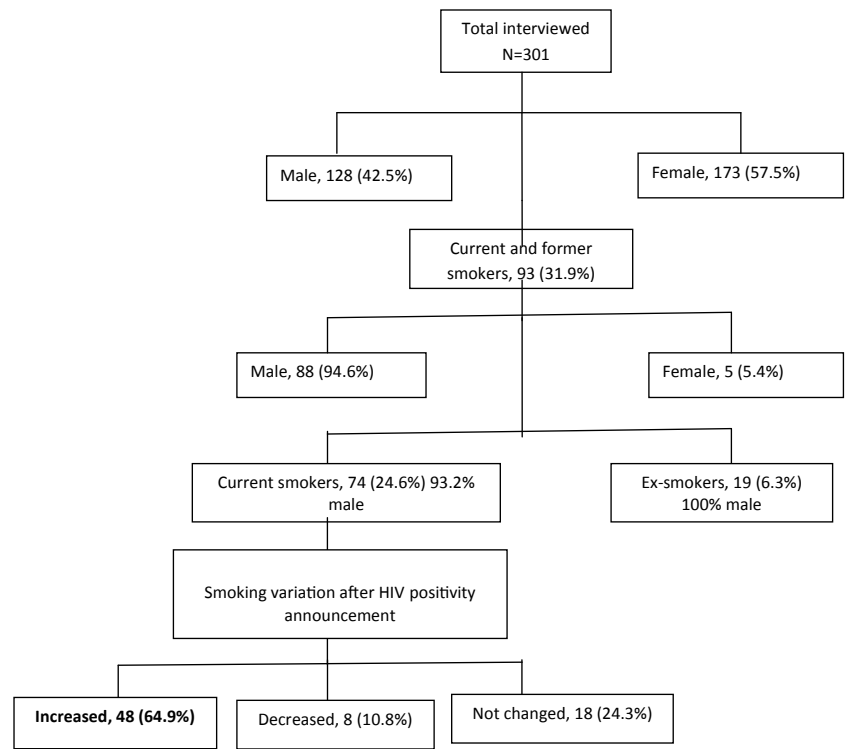

Figure 1: Patients flow chart.

tobacco (current and former smokers). The prevalence of current smokers was $24.6 \%$ (74/301), former smokers was 6.3\% (19/301) and $69.1 \%$ (208/301) have never smoked (Figure 1). Smoking (current and former) was more likely to be associated to male gender $93.2 \%(69 / 74)$, $\mathrm{OR}=39.3$ [(15.1-102.1), $\mathrm{p}<0.0001]$. Most of the smokers, $86.5 \%(64 / 74)$ and $78.9 \%(15 / 19)$ of former-smokers have been informed of their HIV infection at least 6 months before their enrollment in the study. Among of the 93 participants exposed to tobacco $15(16.1 \%)$ have been treated in the past for tuberculosis disease while $13(6.3 \%)$ for never smoked group. Smokers has 3 times more chance to get tuberculosis disease than no smoking population $(\mathrm{OR}=2.88 ; \mathrm{P}=0.0064)$. Diagnosed chronic cough was found to be associated to smoking with $45.2 \%(42 / 93)$. Whereas $22.6 \%(47 / 208)$ of never smoked group [OR=2.82 (1.67-4.75), $\mathrm{p}=0.000073$ ] (Table 2).

\section{Smoking initiation}

Most of the current smokers (71.6\%) (53/74) reported that they begin smoking in a "grin" (a place where friends get together to chat any topics around green tea). Others reason such as work load (20.3\%) $(15 / 3)$ was reported. Only $4.0 \%$ reported to have started smoking after been aware of their HIV infection status.

\section{Smoking quantification}

Tobacco consumption level was calculated in pack per year using the formula (PXY; $\mathrm{P}=$ number of pack per day $\mathrm{Y}=$ =year of smoking). Current smokers who smoked 1 to 5 packs in a year were $39.2 \%$; $54 \%$ smoked 6 to 20 and $6.8 \%$ smoked more than 20 packs in a year.

\section{Smoking behavior}

Amount the 74 smokers, 48 (64.3\%) increases their consummation of cigarette after their HIV positive testing result announcement. According to the national guidelines HIV testing should be accompanied by a pre and post counseling. At least 6 months after being informed about their HIV positive status, $93.5 \%$ (43/46) of smokers increases the number of cigarettes they smoked per day. The time has negative impact on the patient decision to increase tobacco consumption $\mathrm{OR}=65.93$ [14.44-300, $\mathrm{p}<0.00001]$ (Table 3). After announcement of the positive 
Page 3 of 5

\begin{tabular}{|c|c|c|c|}
\hline \multicolumn{4}{|l|}{ Sex } \\
\hline & Females & 173 & 57.5 \\
\hline & Males & 128 & 42.5 \\
\hline \multicolumn{4}{|c|}{ Age range (Years) } \\
\hline & $18-35$ & 131 & 43.5 \\
\hline & $36-50$ & 127 & 42.2 \\
\hline & $51-65$ & 41 & 13.6 \\
\hline & $>65$ & 2 & 0.7 \\
\hline \multicolumn{4}{|c|}{ Occupation } \\
\hline & Artist/artisan & 20 & 6.6 \\
\hline & Driver & 14 & 4.6 \\
\hline & Farmer/Workman & 62 & 20.6 \\
\hline & Trader/Seller & 76 & 25.2 \\
\hline & Student & 4 & 1.3 \\
\hline & Civil servant & 36 & 12.0 \\
\hline & Housewife & 83 & 27.6 \\
\hline & Unemployed & 6 & 2.0 \\
\hline \multicolumn{4}{|c|}{ Education level } \\
\hline & Illiterate & 130 & 43.2 \\
\hline & Primary school & 100 & 33.2 \\
\hline & Secondary & 54 & 18.0 \\
\hline & University & 17 & 5.6 \\
\hline \multicolumn{4}{|c|}{ Matrimonial status } \\
\hline & Married & 193 & 64.1 \\
\hline & Single & 55 & 18.3 \\
\hline & Divorced & 20 & 6.6 \\
\hline & Widower/widow & 33 & 11.0 \\
\hline \multicolumn{4}{|c|}{ HIV type } \\
\hline & Type 1 & 294 & 97.7 \\
\hline & Type 2 & 5 & 1.7 \\
\hline & Type $1+2$ co-infection & 2 & 0.6 \\
\hline \multicolumn{4}{|c|}{ HIV test circumstances } \\
\hline & Disease investigation & 237 & 78.7 \\
\hline & Partner HIV-positive & 22 & 7.3 \\
\hline & Blood donor & 7 & 2.3 \\
\hline & Health assessment & 35 & 11.6 \\
\hline \multicolumn{4}{|c|}{ Traveled to another country } \\
\hline & None & 178 & 59.0 \\
\hline & Africa & 114 & 38.0 \\
\hline & Other continent & 9 & 3.0 \\
\hline \multicolumn{4}{|c|}{ Started ART } \\
\hline & Yes & 262 & 87.0 \\
\hline & No & 39 & 13.0 \\
\hline \multicolumn{4}{|c|}{$\begin{array}{l}\text { Period of HIV } \\
\text { knowledge }\end{array}$} \\
\hline & $\geq 6$ months & 249 & 82.7 \\
\hline & $<6$ months & 52 & 17.3 \\
\hline
\end{tabular}

Table 1: Patient demographic characteristics.

result of HIV, $45.8 \%(22 / 48)$ of the smokers added 1 to 5 cigarettes to their daily consumption, $50 \%(24 / 48)$ added 6 to 10 cigarettes and $4.2 \%(2 / 48) 11$ to 20 cigarettes in their daily consumption. The majority $66 \%(49 / 74)$ of the smokers still smoke because they were scared of the disease (Figure 2).

\section{Smoking cessation}

According to our smoking knowledge scale, $98.6 \%$ of smokers were classified as level-1 (knew the dangerousness of smoking and continues to smoke) while $100 \%$ of ex-smokers had claimed to know smoking dangerousness and don't smoke anymore. Of those who continue to smoke, $83.8 \%(62 / 74)$ reported that they tried and failed at least one

\begin{tabular}{|c|c|c|c|}
\hline Smoking characteristics & & $\begin{array}{l}\text { Number } \\
(\mathrm{N}=301)\end{array}$ & Percentage (\%) \\
\hline \multicolumn{4}{|l|}{ Smoking status (301) } \\
\hline & Smokers & 74 & 24.58 \\
\hline & Ex-smokers & 19 & 6.31 \\
\hline & Non-smoker & 208 & 69.10 \\
\hline \multicolumn{4}{|l|}{$\begin{array}{l}\text { Occasion leaded smoking } \\
\qquad(\mathrm{N}=74)\end{array}$} \\
\hline & Gathering place & 53 & 71.6 \\
\hline & Work load & 15 & 20.3 \\
\hline & HIV status & 3 & 4.0 \\
\hline & Don't know & 3 & 4.0 \\
\hline \multicolumn{4}{|l|}{$\begin{array}{l}\text { Smoking Variation after } \\
\text { informed }(\mathrm{N}=74)\end{array}$} \\
\hline & Increased & 48 & 64.9 \\
\hline & Decreased & 8 & 10.8 \\
\hline & Not changed & 18 & 24.3 \\
\hline \multicolumn{4}{|l|}{$\begin{array}{l}\text { Number of cigarettes added } \\
\qquad(\mathrm{N}=48)\end{array}$} \\
\hline & 1 to 6 Cigarette & 19 & 39.2 \\
\hline & $\begin{array}{l}6 \text { to } 20 \\
\text { Cigarettes }\end{array}$ & 26 & 54 \\
\hline & $>20$ cigarettes & 6.8 & 6.8 \\
\hline \multicolumn{4}{|c|}{ Sensation after smoking $(\mathrm{N}=74)$} \\
\hline & Relaxation & 65 & 87.8 \\
\hline & Indifferent & 5 & 6.8 \\
\hline & Frustration & 4 & 5.4 \\
\hline \multicolumn{4}{|l|}{$\begin{array}{c}\text { Cessation tobacco tried } \geq 1 \\
\text { time }(\mathrm{N}=74)\end{array}$} \\
\hline & Yes & 62 & 83.8 \\
\hline & No & 12 & 16.2 \\
\hline \multicolumn{4}{|l|}{$\begin{array}{l}\text { Knowledge of tobacco } \\
\text { danger }(\mathrm{N}=301)\end{array}$} \\
\hline & Level 1 & 67 & 22.3 \\
\hline & Level 2 & 01 & 0.3 \\
\hline & Level 3 & 217 & 72.1 \\
\hline & Level 4 & 16 & 5.3 \\
\hline \multicolumn{4}{|l|}{$\begin{array}{l}\text { Cough with expectoration } \\
\qquad(\mathrm{N}=301)\end{array}$} \\
\hline & Mucous & 49 & 16.3 \\
\hline & Mucopurulent & 14 & 4.6 \\
\hline & None & 238 & 79.1 \\
\hline
\end{tabular}

Table 2: Smoking characteristics, behavior and associated factors.

time the smoking cessation. The main reason of their cessation was the effect on their health. The main reason for the failure was the constant thinking of their HIV status.

\section{Discussion}

Our data has showed a predominant females gender (57.5\%). People were young adult $85.5 \%$ between 18 and 50 years old (18-35, $43.5 \%$ and $36-50,42.2 \%)$. The mean age was 38.54 years, HIV-1 infection was predominant with $97.67 \%$ and $87.0 \%$ have been on antiretroviral treatment. Investigating for illness with $78.7 \%$ was the most reason for HIV test. Occupation was housewife in $27.6 \%$, trader in $25.2 \%$. They were married in $64.1 \%, 43.2 \%$ were illiterate, $59.0 \%$ never traveled outside the country and $82.7 \%$ has known status more than 6 months prior to the survey (Table 1). Nguyen et al. [9] reported a mean age of the study participants at 35.5years. The majority was male gender 


\begin{tabular}{|c|c|c|}
\hline Smoking variation after been informed of the HIV positive status & $\mathbf{2 6 \text { months }}$ \\
\hline Increased & 43 & 3 \\
\hline Decreased or not changed & 46 & 23 \\
\hline Total & 28 \\
\hline
\end{tabular}

Table 3: Our data show that $93.5 \%$ (43/46) of HIV-infected smokers who were informed of their HIV infection more than 6 months have increased their number of cigarette smoked. The time has negative impact on the patient decision to increase in tobacco consumption OR=65.93 [14.44-300, $p<0.00001]$.

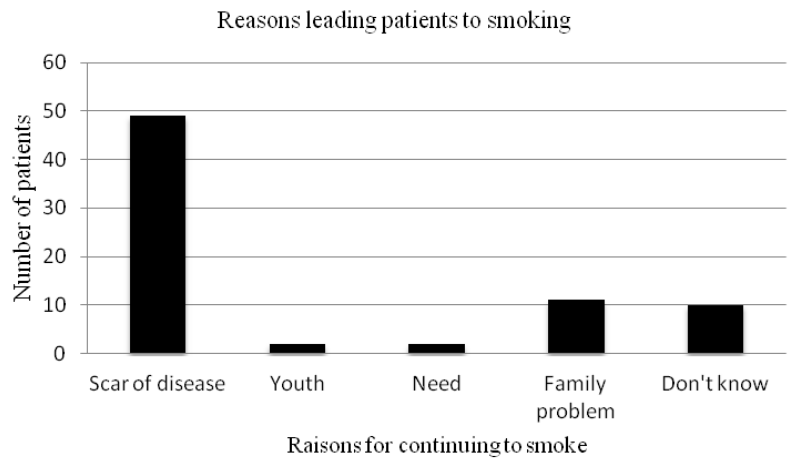

Figure 2: Reasons keeping HIV individuals smoking after been informed of the HIV status.

(58.7\%), with 57.4\% with high school education level, an education level of less than a high school education (57.4\%), lived with a spouse/ partner (61.2\%), and was currently working (79.5\%), the mean duration of HIV infection was 6.0 years. But, Torres et al. [4] in Brazil found a majority of male (65.4\%). Our data found, $24.6 \%$ smokers, $6.3 \%$ former and 69.1 never smoker despite the predominance of female $57.5 \%$ (Figure 1). Smokers were more likely to be male with $93.2 \%$ ( $\mathrm{p}<0.0001$ ). The smoking prevalence in Malian general population is $17 \%$ and $32 \%$ of men are smoker again $3 \%$ of women [7]. The number of cigarette smoked per day ranged from $1-5 ; 6-20$ and more than 20 packs a year respectively in $39.2 \%, 54 \%$ and in $6.8 \%$. Shirley et al. [10] in New York have found a similar frequency of $29 \%$ of smokers from $200 \mathrm{HIV}$-infected patients despite male predominance of $84 \%$. Torres et al. [3] have reported in a population of 2,775 HIV-infected individuals $29.9 \%$ of current smokers, $23.9 \%$ of former smokers and $46.2 \%$ never smoked Oka et al. in Japan have found $40 \%$ of smoker in $100 \mathrm{HIV}$ infected individuals [11]. Nguyen et al. [9], the prevalence of current was higher $36.1 \%$. Current and former smokers were more likely to be males compared to never smokers. The current smoking proportion was much higher in males $(59.7 \%)$ than females $(2.6 \%)$. Nearly $27 \%$ smoked within 5 min of waking and $62.2 \%$ of participants smoked less than 10 cigarettes per day. HIV-positive males were 23.4 times (95\% CI=11.6-47.3,) more likely to currently smoke than HIVpositive females. After announcement of their serology positivity result $45.8 \%(22 / 48)$ of smokers added 1 to 5 cigarettes to their daily consumption, 50\% (24/48) increase 6 to 10 cigarettes and 4.2\% (2/48) 11 to 20 cigarettes per day to their daily consumption. Our study, (Table 3 ), found a frequency of tuberculosis 3 times more in smokers than non-smoker $(95 \%, \mathrm{OR}=2.88, \mathrm{P}=0.0064)$. Torres et al. [3], smoker were more likely to get TB $29.9 \%$; $=0.001$. Nancy has reported that both $\mathrm{HIV}$ and smoking are risk factors for suppression of local lung defenses and pulmonary diseases including a variety of bacterial pneumonia, acute bronchitis, and tuberculosis [12].

Crothers et al. [13] has shown in a cohort of patients seen for pulmonary diseases, $80 \%$ of HIV-infected patients were smokers. Helleberg et al. [4], in United States have shown evidence on live expectancy diminution in HIV-infected people smoking than nonsmokers within a proportion of current, previous and never smokers of 46.5, 25.7 and $27.8 \%$, respectively. In an HIV survey, $63 \%$ have reported that they were thinking about quitting. Despite the intention to quit, current smokers in a study have reported having made an average of 2.8 quit attempts since their HIV diagnosis and another group of HIVpositive smokers reported an average of 4.2 previous quit attempts [14].

\section{Study Limits}

We did not assess some characteristics whose could have explained some of the results like tobacco increasing and the reason of tobacco cessation failing. According the Malian culture some characteristics like alcoholism and drug use, sexual orientation are difficult to study due to the religious bias. Also we did not compare with a non HIV population.

\section{Conclusion}

Our data shows that the prevalence of smoking is high in Malian HIV-infected people, but the HIV-infection status announcement did not lead to begin smoking. It has negatively influenced those already smoking to increase their consumption. Also this influence has resisted to any tentative of smoking cessation. A strong smoking cessation program need be added in HIV screening centers to avoid influencing the vulnerability to tobacco dependence. Since we used a bivariate analysis, further multivariate regression analytical method is needed to explore potential confounders.

\section{Author's Contribution}

Study conceived and designed: BB, SD, SDAO, CAKM and MC. Performed the survey: BB, AKM, ED, SS and MC. Analyzed the data: YSS, BB. Wrote the paper: BB, CAKM, YSS, MC, ED, SS, SDao, SD.

\section{Acknowledgement}

We address acknowledgment to all individuals and structures whose have facilitate conducting this study: -All study participants -Rectorat of University of Sciences, Techniques and Technologies of Bamako (USTT-B), Mali -Pneumology and infectious diseases departments at Point G University Hospital - CESAC (Center d'Ecoute, de Soins, d'Accompaniment et de Conrail) of Bamako.

\section{References}

1. Marta C, Montserrat L, Maria M, Esteban M (2015) Effects of tobacco smoking on HIV-infected individuals. AIDS Rev 17: 47-55.

2. Damon JV, Faith EF, Meredith K, Buchberg, Yisheng Li, et al. (2014) The influence of HIV disease events/stages on smoking attitudes and behaviors: Project STATE (Study of Tobacco Attitudes and Teachable Events). BMC Public Health 14: 149.

3. Torres TS, Luz PM, Derrico M, Velasque L, Grinsztejn E, et al. (2014) Factors associated with tobacco smoking and cessation among HIV-infected individuals under care in Rio de Janeiro, Brazil. PLoS ONE 9: e115900.

4. Helleberg M, Margaret TM, Suzanne MI, Francois D, Peter R, et al. (2015) Smoking and life expectancy among HIV-infected individuals on antiretroviral therapy in Europe and North America. AIDS 29: 221-229.

5. Davidsen M, Kjoller M, Helweg-Larsen K (2011) The Danish National Cohort Study (DANCOS). Scand J Public Health 39: 131-135.

6. Cellule de Planification et de Statistique (CPS/SSDSPF), Institut National de la Statistique (INSTAT/MPATP), INFO-STAT et ICF International (2014) Enquête Démographique et de Santé au Mali 2012-2013. Rockville, Maryland, USA. 
Citation: Baya B, Maiga CAK, Sarro YdS, Cisse M, Dao E, et al. (2016) Relationship between HIV Positive Status Announcement and Smoking among Infected-Individuals in Bamako, Mali. J AIDS Clin Res 7: 617. doi:10.4172/2155-6113.1000617

Page 5 of 5

7. WHO global report on trends in prevalence of tobacco smoking (2015) WHO

8. Emily BA, Peihua Gu, Keri T, Rajita S (2012) Effects of cumulative stress and impulsivity on smoking status. Hum Psychopharmacol 27: 200-208.

9. Nguyen NPT, Tran BX, Hwang LY, Markham CM, Swartz MD, et al. (2015) Prevalence of cigarette smoking and associated factors in a large sample of HIV-positive patients receiving antiretroviral therapy in Vietnam. PLoS ONE 10: e0118185.

10. Shirley DK, Kesari RK, Glesby MJ (2013) Factors associated with smoking in HIV-infected patients and potential barriers to cessation; AIDS Patient Care STDS 27: 604-612.
11. Fukuko O, Toshio N, Miki O, Mizue S, Akihiro I, et al. (2013) Influence of smoking on HIV infection among HIV-infected Japanese men. J Infect Chemother 19 542-544.

12. Nancy R (2009) Cigarette Smoking and HIV: More Evidence for Action. AIDS Educ 21: 106-121.

13. Kristina C, Laurence H, Joseph LG, Matthew BG, Sheldon TB, et al. (2010) $\mathrm{HIV}$ infection and risk for incident pulmonary diseases in the combination antiretroviral therapy era. Am J Respir Crit Care 183: 388-395.

14. Alan RL, Harry AL (2012) Smoking and HIV: Prevalence, health risks and cessation strategies. Curr HIVIAIDS Rep 9: 223-230. 